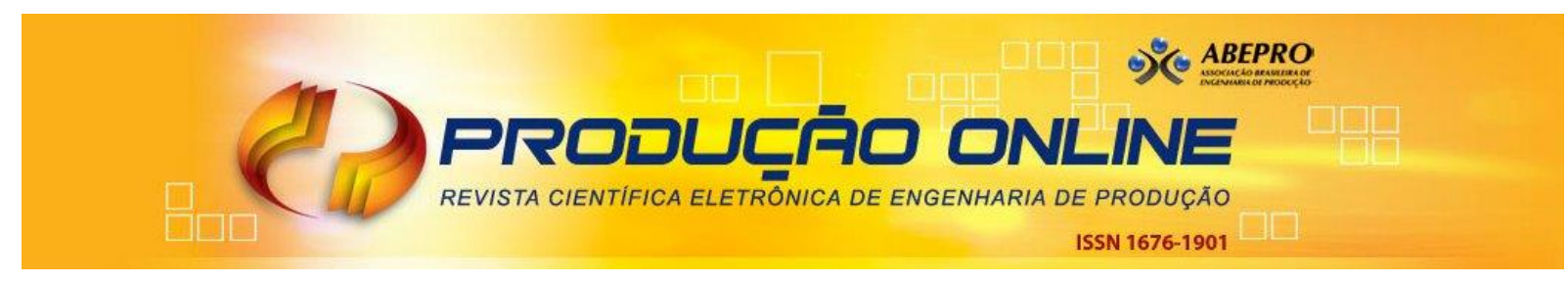

\title{
A VERTICALIZAÇÃO DAS OPERAÇÕES LOGÍSTICAS DE UM GRUPO DO SETOR SUCROENERGÉTICO
}

\section{VERTICALIZATION OF THE LOGISTICAL OPERATIONS OF A GROUP OF THE SUCROENERGETIC SECTOR}

\author{
Rodrigo Duarte Soliani* E mail: rdsoliani@hotmail.com \\ Ana Rita Tiradentes Terra Argoud** E mail: ana.terra.argoud@gmail.com \\ *Universidade de Ribeirão Preto (UNAERP), Ribeirão Preto, SP \\ ${ }^{* *}$ Faculdade de Tecnologia de São Carlos (FATEC), São Carlos, SP
}

\begin{abstract}
Resumo: Fazer ou comprar é uma decisão importante para os executivos na hora de compor a estratégia de crescimento de uma organização. Os limites horizontais e verticais são fatores fundamentais a serem considerados. O objetivo principal deste estudo é compreender a verticalização no agronegócio, com foco nas operações logísticas de escoamento da produção de açúcar, enfatizando o processo de fusão entre uma empresa logística pertencente a um grupo sucroenergético, com a maior companhia ferroviária em extensão de malha no país. Para tanto, utilizou-se da metodologia de pesquisa caracterizada como exploratória, qualitativa e estudo de caso. Essa pesquisa possibilitou concluir que a Cosan aplicou a estratégia de verticalização fundada na Visão Baseada em Recursos; a fusão, entre e a Rumo e a ALL, gerou a maior empresa de operações logística do Brasil; o processo de fusão repercutiu não somente no setor sucroenergético, mas também no setor de grãos; a Cosan vem realizando investimentos de melhoria da infraestrutura com o intuito de ampliar a malha ferroviária e solucionar os gargalos, tendo como consequência a elevação da eficiência e redução dos custos operacionais, que resultaram, na comparação com 2016 , no crescimento do EBITDA em $36 \%$; aumento de $28 \%$ no volume total transportado; melhora de $4 \%$ no indicador do custo variável ferroviário unitário; e ganho de $9 \%$ no indicador do consumo de Diesel.
\end{abstract}

Palavras-chave: Estratégia de crescimento. Ferrovia. Fusão. Logística.

\begin{abstract}
Make or buy is an important decision for executives when composing the growth strategy of an organization. The horizontal and vertical limits are fundamental factors to be considered. The aim of this study is to understand the vertical integration in agribusiness, focusing on logistics operations flow of sugar production, emphasizing the process of merger between a logistics company belonging to a sugar and ethanol group, with the largest railway company in knitted extension in the country. For this purpose, it was used the research method characterized as exploratory qualitative and case study. This research made it possible to conclude that Cosan applied the verticalization strategy based on a Resource Based View; the merger, between and Rumo and ALL, generated the largest logistics operations company in Brazil; the merger process had repercussions not only on the sugar-energy sector, but also on the grain sector; Cosan has been investing in improving the infrastructure with the aim of expanding the railway network and solving the bottlenecks, resulting in an increase in efficiency and a reduction in operating costs, which, in comparison with 2016, resulted in an EBITDA growth of 36\%; $28 \%$ increase in total volume transported; improvement of $4 \%$ in the variable unit cost indicator; and a $9 \%$ gain in the Diesel consumption indicator
\end{abstract}

Keywords: Growth strategy. Railroad. Fusion. Logistics. 


\section{INTRODUÇÃO}

A dinâmica do mercado, cada vez mais intensa, tem motivado as empresas a buscarem alternativas para assegurar a melhoria do desempenho, tornando-se mais competitivas ou se transformando em referência no segmento de atuação. Um dos caminhos para se alcançar melhores resultados, é adotar táticas de evolução, que repercutam em vantagem competitiva em relação aos seus concorrentes. $O$ cenário de atuação das empresas demonstra que em termos de competição, somente os mais preparados e com visão ampla do negócio são os que vão sobreviver. Por essa perspectiva, a estratégia de crescimento constitui-se como uma ferramenta fundamental para a gestão empresarial na articulação das ações em um ambiente complexo e volátil, como o setor sucroenergético, e apresenta-se como importante objetivo, organizar a empresa para atuar no ambiente crítico de grandes dificuldades (VINHAS, 2017).

O Brasil, com relação à agroindústria açucareira, tem tradição secular. Tratase de um sistema de produção que se notabilizou desde o início das atividades na região Nordeste, onde se sustentava uma monocultura extensiva, nos latifúndios, no uso da mão de obra escrava e no grande capital. As características do modelo atual utilizado ainda revelam a plantação de cana-de-açúcar em grandes áreas e a significativa necessidade de aportes financeiros, ou seja, predomina o volume amplo em função da economia de escala relacionada a esse sistema de produção. Ressalta-se que para desempenho do processo utilizado pelo setor sucroenergético brasileiro, houve a necessidade de desenvolvimento tecnológico para a área agrícola, industrial e logística (GARCIA; LIMA; VIEIRA, 2015).

O uso do etanol como combustível no Brasil foi motivado pela crise financeira que afetou o setor açucareiro no começo do século XX, concomitantemente à crise de 1929, que atingiu a economia capitalista. Essa situação levou à mistura obrigatória de etanol à gasolina importada, sendo o ponto de partida para a consolidação de um importante segmento da economia brasileira, que se mostra alternativo aos efeitos nocivos dos combustíveis fósseis ao meio ambiente (GARCIA; LIMA; VIEIRA, 2015). Entretanto, o comportamento do mercado interno e externo impulsionou o setor sucroenergético a adotar alternativas estratégicas de crescimento, provocando mudanças no cenário, quando observado as unidades e o panorama nacional. Ampliações da produção agrícola e industrial, fusões e incorporações e outras alternativas podem 
figurar como estratégias de crescimento, no entanto, a essência dessa proposta precisa estar em sintonia com os interesses da organização e dos investidores do negócio. Enfim, o propósito da estratégia de crescimento fica por conta da elevação das vendas e participação no mercado (VINHAS, 2017).

A participação das operações logísticas é fundamental para as pretensões da organização. Promover a movimentação de produtos para atender as demandas do mercado consta da pauta de ações da gestão empresarial de qualquer setor produtivo. Porém, em muitos casos, a complexidade da situação ressalta a importante decisão em "fazer" ou "comprar". As análises de viabilidade são essenciais para os direcionamentos para a melhor tomada de decisão. Trabalhar na horizontalidade ou integração da verticalização das operações produtivas reflete em impactos significativos para a organização, principalmente, quanto às prioridades competitivas (MOBUS; MAÇADA, 2013).

Os aspectos verticais e horizontais são fatores relevantes a serem considerados na decisão pelo planejamento, estruturação e empreendimento das ações estratégicas de crescimento da organização (FREITAS; ANDRADE; BORDEAUX-REGO, 2015). Por este aspecto, tem-se o seguinte questionamento: quais os benefícios que a estratégia de crescimento suportada pela verticalização pode proporcionar à organização pelo desempenho de suas atividades?

No empenho em buscar respostas, este estudo tem como objetivo principal compreender a verticalização no agronegócio, com foco nas operações logísticas de escoamento da produção de açúcar, enfatizando o processo de fusão de uma empresa logística pertencente a um grupo sucroenergético, com a maior companhia ferroviária em extensão de malha no país.

\section{A IMPORTÂNCIA DO SETOR SUCROENERGÉTICO PARA O BRASIL}

A importância da participação do setor sucroenergético na economia do Brasil pode ser confirmada pelos resultados apresentados pela União da Indústria de Canade-Açúcar (UNICA), entidade que representa os maiores produtores de açúcar, álcool e bioenergia brasileiros. Dentre os números finais da safra 2016/17, publicados no Relatório Final da Safra 2016/2017, verificou-se que a produção de açúcar foi de aproximadamente 39 milhões de toneladas e a de álcool em torno de 27 milhões de metros 
cúbicos, considerando que para este feito, foram processadas pouco mais de $651 \mathrm{mi}$ Ihões de toneladas cana-de-açúcar, provenientes de uma área ocupada por volta de 11 milhões de hectares (UNICA, 2017a).

A UNICA e o Centro Nacional das Indústrias do Setor Sucroenergético e Biocombustíveis (CEISE Br), ao traçarem um panorama da agroindústria canavieira, revelam que são mais de 380 unidades produtoras espalhadas pelo país, com oportunidades de empregos formais diretos para mais de 950 mil trabalhadores, e cerca de 70 mil produtores rurais de cana-de-açúcar independentes, atuando em mais de 1.000 municípios. Em 2015, o setor gerou US\$ 8,5 bilhões em divisas externas, ficando em quarto lugar na pauta de exportação do agronegócio nacional. Registrou um Produto Interno Bruto (PIB) de aproximadamente US\$ 40 bilhões, correspondendo por $2 \%$ do PIB brasileiro. O estudo ainda ressalta que a movimentação bruta anual da cadeia sucroenergética, em valores, supera US\$ 100 bilhões. O Brasil é o maior produtor e exportador mundial de açúcar (respondendo por $20 \%$ da produção e por $40 \%$ da exportação global) e o segundo maior produtor de etanol do mundo (UNICA; CEISE Br, 2016).

A respeito dos benefícios para o meio ambiente gerados pelo setor, a utilização do etanol como combustível para abastecer uma frota de mais de 26 milhões de veículos flex, correspondentes por $70 \%$ da do total de carros leves que circulam no Brasil, tem representado, de acordo com a ferramenta da UNICA intitulada "Carbonômetro", uma redução das emissões de gases de efeito estufa (GEE) em mais de 408 milhões de toneladas de $\mathrm{CO} 2$, resultado este considerado a partir do lançamento do carro flex fuel em 2003 (UNICA, 2017b; CEISE Br, 2016).

Em termos de comparação, este volume é equivalente a soma das emissões dos sete países europeus em 2012, apresentados na Tabela 1. Este é tido como o mais bem-sucedido programa de combustível alternativo já desenvolvido no mundo (UNICA, 2017b). 
Tabela 1 - Soma das emissões de $\mathrm{CO} 2$

\begin{tabular}{cc}
\hline Países & Emissão (milhões/t) \\
\hline Eslovênia & 16 \\
Irlanda & 35 \\
Portugal & 51 \\
Hungria & 51,1 \\
Suécia & 55 \\
Áustria & 66,7 \\
Bélgica & 139,1 \\
Total & 413,9 \\
\hline
\end{tabular}

Fonte: Adaptado de UNICA (2017b)

Através da metodologia de cálculo usada pela organização não-governamental SOS Mata Atlântica, para se obter esse volume de redução das emissões obtido no Brasil, seria necessário realizar o plantio e manutenção de quase 3 bilhões de árvores ao longo de 20 anos. Segundo a metodologia da ONG, são necessárias 7,14 árvores para absorver uma tonelada de carbono (UNICA, 2017b).

\subsection{Operações logísticas no setor sucroenergético}

De acordo com o Ministério da Agricultura, Pecuária e Abastecimento (MAPA), a logística de transporte da produção agroindustrial contempla a utilização de diferentes modais e infraestrutura, e se consagra como elemento estratégico para o crescimento e competitividade do agronegócio brasileiro (BRASIL, 2017).

As unidades produtoras que integram o setor sucroenergético possuem armazéns de açúcar e de etanol, com a finalidade de guardar os produtos por longos períodos de tempo, sendo estratégicos no sentido de regular e organizar o planejamento de transporte e operações logísticas de distribuição (VIAN; MARIN, 2017).

O agronegócio brasileiro nos últimos anos tem apresentado evolução no quesito produtividade, no entanto, os elevados custos logísticos gerados pela ineficiência da infraestrutura, têm impactado na perda da competitividade do produto nacional frente ao mercado internacional. O custo brasileiro para se movimentar o produto da fonte de produção ao porto de embarque para exportação é cerca de quatro vezes maior que em países como os Estados Unidos ou Argentina (FREITAS, 2015).

Freitas (2015) relata que em um estudo realizado pela Empresa Brasileira de Pesquisa Agropecuária (EMBRAPA), identificou-se que se o Brasil fizesse investimentos para a melhoria da infraestrutura logística do país, solucionando os problemas 
referentes ao escoamento de produtos do agronegócio, os produtores teriam um ganho na faixa de $35 \%$ superior ao atual. Esse retrato mostra que o país não é assertivo e eficaz nos poucos investimentos que são feitos em logística. Ademais, especialistas no assunto entendem que, além dos investimentos necessários para o melhor desempenho da logística de transporte, os problemas regulatórios e a insegurança jurídica acabam inibindo os aportes financeiros para solucionar os gargalos de infraestrutura (FREITAS, 2015).

Com relação as ações estabelecidas para que o açúcar e etanol cheguem ao destino final, o setor sucroenergético utiliza-se de empresas de distribuição e exportação especializadas. No âmbito do mercado interno, o transporte desses produtos é realizado, principalmente, pelo modal rodoviário, com caracterização de uma ligação direta entre a indústria e o mercado consumidor. $\mathrm{O}$ uso de outros sistemas de transporte de açúcar e etanol, como o ferroviário e o aquaviário, tem pouca aplicação. Entretanto, são setores que têm apresentado crescimento no Brasil pela eficiência quando comparado ao transporte rodoviário para operações de longas distâncias (VIAN; MARIN, 2017).

Com atenção ao processo de exportação, as operações logísticas de transporte do setor sucroenergético apresentam um grau de complexidade maior, visto que podem ser realizadas pelo uso de rodovias, ferrovias e, no caso do etanol, pela utilização de etanolduto, que liga as destilarias e as usinas aos portos. Para que o porto possa proceder à exportação de etanol, por ser um produto inflamável, é fundamental que se tenha uma infraestrutura adequada para armazenagem e carregamento para os navios. Com relação ao açúcar, são necessários armazéns para estocagem no porto, sendo que o produto pode ser exportado a granel ou ensacado (VIAN; MARIN, 2017).

\subsection{Verticalização no agronegócio}

Agronegócio é a representação dos negócios relacionados com a agricultura e pecuária sob a perspectiva econômica. Diz respeito às operações e transações que são realizadas desde a fabricação dos suprimentos agropecuários, o processo produtivo nas propriedades, até o preparo e distribuição dos produtos agropecuários e seus derivados na forma in natura ou industrializados (ARAÚJO, 2013). 
A integração ou trabalho conjunto entre empresas é um modelo de atuação dentro da agroindústria no sentido de atender as demandas, visto que reflete o objetivo das organizações em elevar o plano de atividades da empresa, dentro de um mesmo ambiente de negócios, tanto no começo da cadeia produtiva (fornecimento) como para o término (distribuição). Trata-se de uma situação que pode acontecer de maneira total ou parcial, desde que repercuta na melhoria da competitividade da organização (BERTÁGLIA, 2016).

No âmbito do agronegócio, a verticalização é configurada pela concatenação de um grupo de atividades de produção e agroindustrialização de produtos que, em determinadas situações, pode ser ampliada até em etapas posteriores ao processo de produção, atingindo as fases iniciais de comercialização (ARAÚJO, 2013).

A integração vertical na organização também pode ser entendida como o nível de operacionalização do processo de produção, da estrutura e de serviços na cadeia de suprimentos. A verticalização é mais ou menos evidente dependendo da quantidade de processos que são envolvidos e executados sob a gestão da empresa, ao invés de contratação de prestadores de serviços para os desempenharem (RITZMAN; KRAJEWSKI, 2009).

Observando a perspectiva de cadeias produtivas no agronegócio, a integração vertical pode se destacar da seguinte forma: para frente, quando a organização investe mais nos canais de distribuição, como centros próprios, armazéns, locais de venda, às vezes até adquirindo empresas clientes; e para trás, onde tem-se a articulação da empresa em sentido dos fornecedores de matérias-primas (RITZMAN; KRAJEWSKI, 2009).

Geralmente, a verticalização representa o efeito de combinações institucionais evidenciadas com base nos interesses entre participantes da mesma cadeia, com compartilhamento de tecnologias e informações, habilidades/competências e infraestrutura, sob o propósito de produzir vantagens mútuas, em derivação das integrações verticais e horizontais (CALLADO; CALLADO, 2015).

\section{METODOLOGIA}

Este estudo analisa a fusão entre a Rumo Logística, subsidiária da Cosan S. A., e a América Latina Logística (ALL), maior companhia ferroviária em extensão de malha no país. Este processo teve início no ano de 2014 em função de divergências 
oriundas de contratos para o transporte de açúcar entre a Rumo Logística e a ALL, referente a anos anteriores, e contou com autorização do Conselho de Administração de Defesa Econômica (CADE) e da Agência Nacional de Transportes Terrestres (ANTT) em 2015.

Tratando-se de uma observação de um caso de incorporação ou fusão e com o propósito de associá-lo com um contexto teórico, procurou-se empreender uma metodologia de pesquisa com uma perspectiva de abordagem qualitativa, dado que 0 estudo tem como preocupação fundamental a análise do mundo empírico em seu ambiente natural, se caracterizando por utilizar diversas formas de obtenção das informações, como a pesquisa bibliográfica e o estudo de caso. Já quanto ao tipo, ela é classificada como exploratória, posto que este tipo de pesquisa tem como finalidade proporcionar um maior entendimento do problema, tornando-o mais explícito e formando hipóteses, caracterizada como um estudo de caso pelos procedimentos, segundo Prodanov e Freitas (2013).

A coleta de informações para a realização deste estudo se valeu de artigos científicos disponíveis nas bibliotecas eletrônicas SPELL, SciELO, Periódicos Capes, além de materiais disponíveis nas bases de dados da internet.

\section{GRUPO SUCROENERGÉTICO ESTUDADO}

A história da Cosan começou no ano de 1936 com o início das operações da usina Costa Pinto, localizada no município de Piracicaba (SP). Ao longo dos anos a empresa foi diversificando seus negócios, investindo outros setores, além do sucroalcooleiro. A COSAN tem ações listadas na Bolsa de Valores de São Paulo desde 2005 e na NYSE (New York Stock Exchange) desde 2007.

Por meio de seus negócios, integra o setor sucroenergético brasileiro, produzindo e exportando etanol e açúcar; produz energia elétrica a partir do bagaço da cana; distribui de gás natural; atua na distribuição de combustíveis e lubrificantes. $\mathrm{Na}$ Tabela 2 a seguir, pode-se observar o portfólio grupo Cosan (COSAN, 2018a). 
Tabela 2- Principais empresas do grupo Cosan

\section{EMPRESAS}

$\begin{array}{cc}\text { Raízen Combustíveis } & \begin{array}{c}\text { Segunda maior distribuidora de combustíveis do país, com mais de } \\ 67 \text { terminais de distribuição e } 6.000 \text { postos de serviços espalhados } \\ \text { pelo Brasil sob a marca Shell. }\end{array} \\ \text { Raízen Energia } & \begin{array}{r}\text { Principal fabricante de etanol de cana-de-açúcar do Brasil e a maior } \\ \text { exportadora individual de açúcar de cana no mercado internacional. } \\ \text { Comgás }\end{array} \\ \text { Presente em } 177 \text { cidades do Estado de São Paulo, é a maior distri- } \\ \text { buidora de gás natural do Brasil. }\end{array}$

Fonte: Adaptado de Cosan (2018a).

Com o pensamento direcionado para a inovação, competitividade, eficiência e respeito ao meio ambiente, a Cosan faz investimentos em setores importantes para o desenvolvimento do Brasil. Participando dos setores de energia e logística, com pessoal qualificado e comprometido, tem contribuído para a construção das bases de um crescimento consistente e sustentável do país (COSAN, 2018a).

Da joint venture entre a Cosan e a Shell, surgiu a Raízen, que tem forte atuação no setor de energia e é destacada como a maior produtora individual de açúcar e etanol, como uma gigante na cogeração de energia no Brasil e também por figurar entre as maiores distribuidoras de combustíveis do país (COSAN, 2018b).

A Raízen é a principal fabricante de etanol de cana-de-açúcar do Brasil, produzindo cerca de 2 bilhões de litros de etanol por ano. Também, produz 4,2 milhões de toneladas de açúcar, em seus variados tipos, e comercializa 1,8 milhão de MWh de energia elétrica anualmente. Com relação à distribuição de combustíveis, tem abrangência no território nacional com mais de 6.000 postos Shell, presença em 54 aeroportos e operações em 67 terminais. Além dessas atuações, tem participação em vários outros negócios, no entanto, sempre procurando investir em soluções eficientes que assegurem o sincronismo entre a rentabilidade, produtividade e sustentabilidade (COSAN, 2018b). 
A Rumo Logística é uma empresa resultante da fusão entre a Rumo e a ALL, operação esta que é tema do trabalho. É a maior operadora logística com base ferroviária independente da América Latina. Disponibiliza um leque de opções em serviços, com uma plataforma de transporte intermodal moderna e integrada, com potencial para transporte e elevação no Porto de Santos para cerca de 19 milhões de toneladas de produtos agrícolas e industriais por ano (RUMO, 2018).

Atua com quatro concessões ferroviárias no Brasil e possui uma estrutura com 12,9 mil quilômetros de malha ferroviária, que passa pelos territórios de seis estados (São Paulo, Paraná, Santa Catarina, Rio Grande do Sul, Mato Grosso e Mato Grosso do Sul), fazendo a interligação entre os centros produtores, polos consumidores e portos marítimos. Possui também 1 mil locomotivas, 27 mil vagões e 12 mil funcionários diretos e indiretos (RUMO, 2018).

O histórico da Rumo mostra seu início em 1993 e no transcorrer do tempo fatos relevantes foram acontecendo numa ordem que caracterizou transformações e crescimento, o que resultou na empresa com o porte e capacidade operacional com base na eficiência e redução de custos (RUMO, 2018).

\subsection{Empresa ferroviária incorporada}

A empresa ferroviária incorporada pela subsidiária da Cosan, a Rumo Logística, foi a ALL, uma empresa especializada no transporte ferroviário, com recursos estratégicos para as pretensões do processo de verticalização da Cosan (RUMO, 2016b). A ALL era considerada como a maior empresa independente de logística da América Latina. Criada em 1997 para desempenho das atividades de transporte ferroviário pela Malha Sul do país, através da concessão da Rede Ferroviária Federal (RFFSA), expandiu sua atuação no setor de logística no Brasil. Sua operação evidenciou-se em regiões responsáveis por mais de $80 \%$ do PIB nacional e nos quatro portos por onde é exportado o maior volume dos grãos produzidos no país (ALL, 2014).

Sediada em Curitiba, trabalhava com quatro concessões (ALL Malha Sul S. A., ALL Malha Oeste S. A., ALL Malha Paulista S. A. e ALL Malha Norte S. A.), que somavam 12 mil quilômetros de ferrovias, correspondendo a $45 \%$ da malha ferroviária total do país. A estrutura operacional contava com 12 unidades de produção, com oficinas de manutenção de vagões e locomotivas e locais de abastecimento em seis 
estados (Paraná, Rio Grande do Sul, Santa Catarina, São Paulo, Mato Grosso e Mato Grosso do Sul). Entre os principais produtos movimentados pela ALL, estão commodities agrícolas (como milho, soja, farelo de soja e açúcar) e produtos industrializados (ALL, 2014).

\section{O PROCESSO DE VERTICALIZAÇÃO DO GRUPO COSAN}

O processo de verticalização do grupo Cosan teve sua caminhada enfrentando percalços e dificuldades, no entanto, definições estratégicas foram determinantes para que os direcionamentos fossem consolidados e resultados pudessem ser alcançados. Com uma gestão organizacional voltada ao crescimento, diante da produção de açúcar e etanol das unidades integrantes do grupo e sua distribuição nos mercados interno e externo, foi necessário viabilizar e aprimorar o processo logístico de transporte. A necessidade de ter eficiência logística na exportação motivou a Cosan a negociar com a Rezende Barbosa S. A. Administração e Participações (RB) e, em 2008, criaram a Novo Rumo Logística S. A. (Novo Rumo) e a Rumo Logística S.A. (Rumo), que passariam a controlar a Cosan Portuária. Nessa mesma época a Cosan e a RB acordaram um instrumento particular de compromisso de venda e compra de ações e outras avenças, quando a Cosan adquiriu 49\% do Teaçu Armazéns Gerais S. A., que na época era proprietário de um terminal portuário de exportação de açúcar localizado em Santos, pertencente a RB (RUMO, 2016a).

Fusões e aquisições de empresas são procedimentos que fazem parte da gestão empresarial nos mais diferentes segmentos. Diante de um cenário altamente competitivo, as fusões e aquisições constituem-se como elementos estratégicos de crescimento, observando os recursos disponíveis de uma organização, que podem ser transformados em vantagem competitiva para a empresa adquirente. Estas ações configuram-se como mecanismos que as organizações usam na intenção de conseguir recursos. A VBR é uma estratégia competitiva que direciona a compreensão da empresa pelos seus recursos atuais ou os que deseja possuir para alcançar resultados econômicos melhores (LEITE; AGNOLIN; CARVALHO, 2017).

Recursos, nessa perspectiva, são considerados os ativos, as capacidades, os processos organizacionais, os atributos, as informações e os conhecimentos de propriedade de uma empresa, que podem contribuir para a implementação de estratégias 
dedicadas à melhoria da eficiência e da eficácia (LEITE; AGNOLIN; CARVALHO, 2017). Neste sentido, a Cosan trabalhou em suas articulações estratégicas, procurando incrementar seus recursos operacionais de logística, visando otimizar o processo de transporte de seus produtos, pela negociação e criação da empresa Rumo S. A.

Até o final do ano de 2013 havia um clima de discórdia e desconfiança entre a Rumo, o braço logístico do grupo Cosan, e a ALL, que operava os principais trechos da malha ferroviária brasileira, caracterizando um clima de litígio agudo. Tudo por conta de um contrato firmado em 2009, que dava conta de um acordo evidenciando a ideia simples e lucrativa para as partes, tipo ganha-ganha. A Rumo assumia o compromisso de aportar $R \$ 1,2$ bilhão na malha da $A L L$, para ter assegurado o transporte do seu açúcar pelo interior do estado de São Paulo até o Porto de Santos. No entanto, as coisas não deram tão certo como se esperavam, e o contrato constituiu-se num embate entre as companhias, que terminou em uma câmara de arbitragem, em outubro de 2013 (RYDLEWSKI, 2014).

Diante das circunstâncias, existia um elevado nível de ceticismo entre os dirigentes das empresas com relação ao trabalho em conjunto. Uma alternativa seria uma revisão do contrato, editando uma nova redação e contemplando outros acordos, porém sem sucesso. A Cosan não desejava perder os investimentos feitos, então partiu para uma ofensiva e acabou ficando com $36,5 \%$ da ALL e nove de seus 17 conselheiros. Esse resultado foi considerado um prêmio e possibilitou o controle do negócio (RYDLEWSKI, 2014).

Ressalta-se que a fusão entre a Rumo e a ALL precisou ser aprovada tanto pelo Conselho Administrativo de Defesa Econômica (CADE) quanto pela Agência Nacional de Transportes Terrestres (ANTT). Esta estratégia contribuiu para o crescimento do grupo Cosan, que veio ter destaque em outros investimentos de grande porte e relevância para o mercado, como a compra da operação da Esso no Brasil; formação da joint venture com a Shell, dando origem à Raízen, a maior produtora de açúcar e etanol do Brasil; e a aquisição da Comgás da britânica BG (RYDLEWSKI, 2014).

Assim, deu-se a fusão das empresas Rumo e ALL, conforme demonstra a linha do tempo apresentada na Figura 1. 
Figura 1 - Linha do tempo para a fusão da Rumo com a ALL

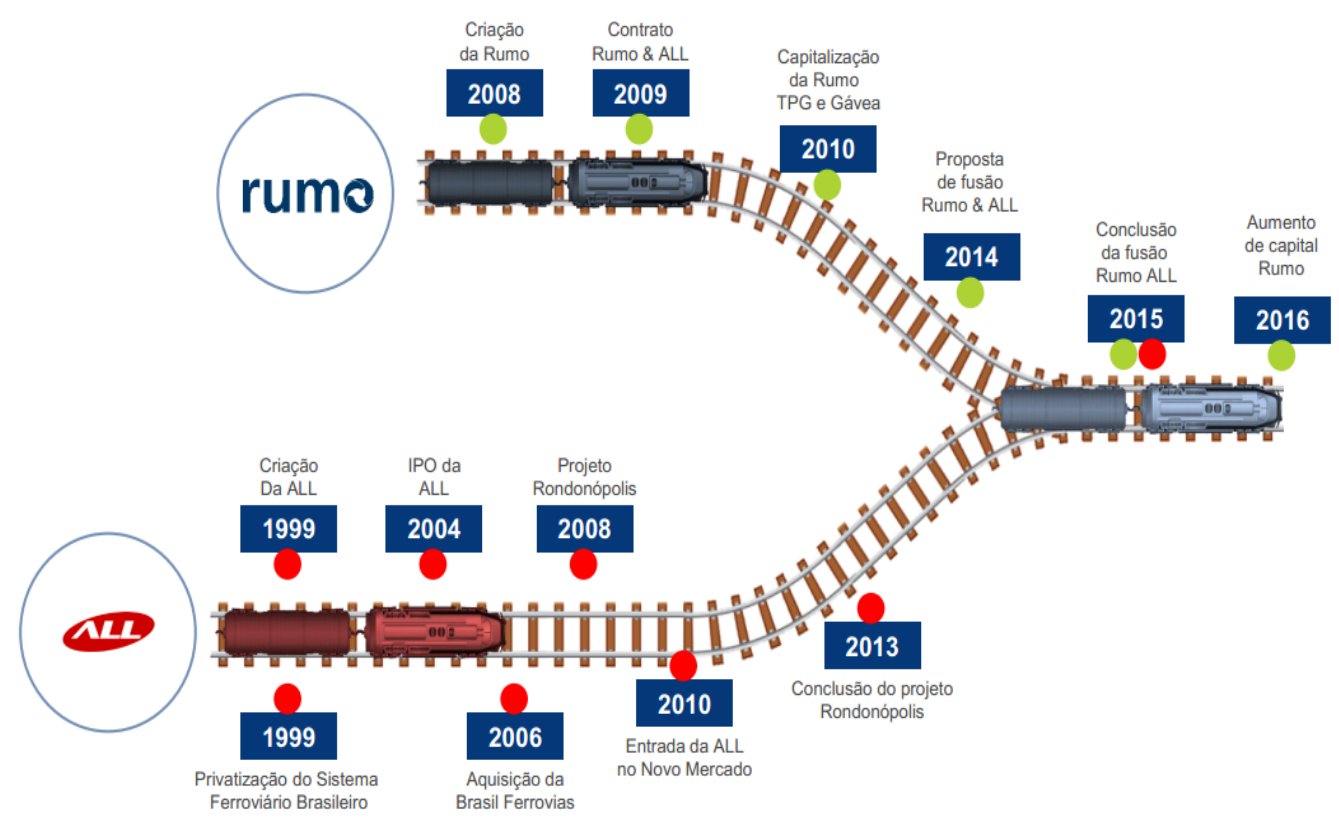

Fonte: Adaptado de RUMO (2016b).

As pretensões com essa negociação foram o aumento do desempenho operacional através da expansão da sua capacidade, a redução dos custos com o aumento da escala e a elevação da eficiência das operações, obtida através da integração operacional. Essa estratégia constituiu-se em uma vantagem competitiva única para a Cosan, dentro do conceito de VBR, pois ao agregar os ativos de sua subsidiária de logística, a Rumo, integrando-os aos ativos da ALL, surgiu uma das maiores empresas nesse segmento atuando no Brasil, apoderando-se de todos os recursos aplicáveis amplamente dentro do transporte e escoamento, armazenagem e operações portuárias, em específico, no segmento de açúcar. Esse processo possibilitou abrir oportunidades para outros investimentos relacionados à commodities, que pudessem ser integrados a esse novo formato logístico resultante da fusão entre a Rumo e a ALL (LEITE; AGNOLIN; CARVALHO, 2017).

A estratégia com essa negociação foi instituir uma empresa de logística com atuação de forma integrada, envolvendo ferrovia, rodovia e porto, em um modelo de negócio que não existe no Brasil. Entretanto, além dos trâmites da consolidação da nova empresa, existe a necessidade de investimentos para a manutenção, que demanda aportes financeiros significativos, diante do volume movimentado e importância dos processos (LEITE; AGNOLIN; CARVALHO, 2017). 
O resultado dessa transação criou um cenário logístico voltado para atendimento às commodities agrícolas por meio de quatro concessões, possibilitando o transporte dos produtos desde a origem até os portos de exportação, abrangendo uma grande área territorial do país, como pode ser observada na Figura 2.

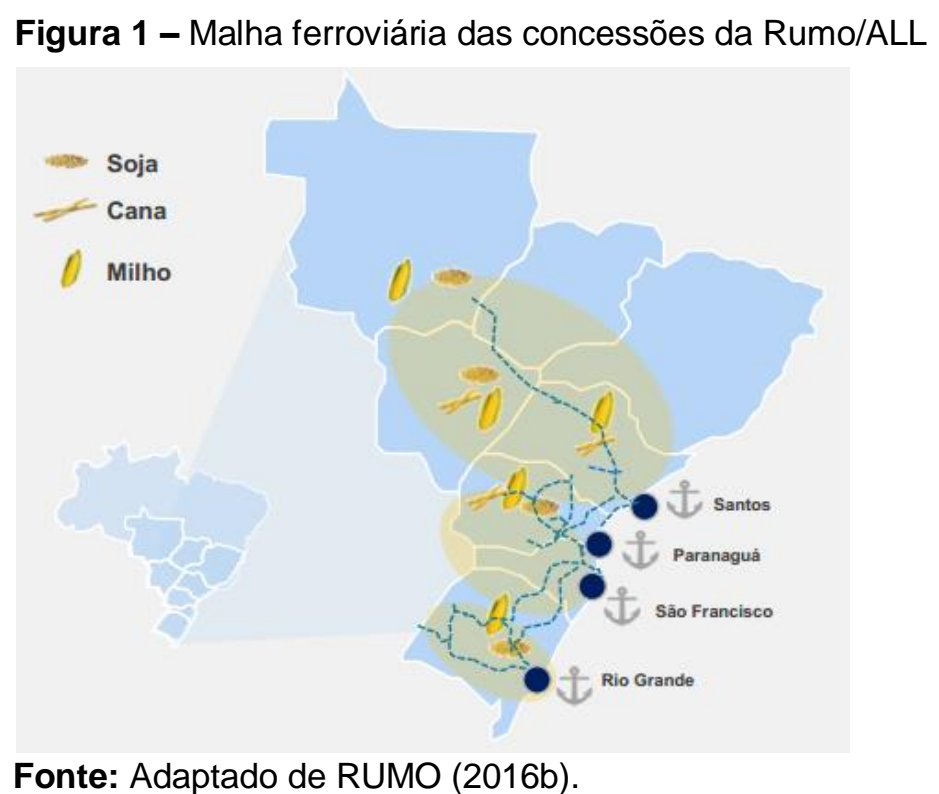

Essa composição operacional estratégica da Cosan representa uma ampliação no escopo de atuação, que foi constituído com o objetivo de atender a demanda, reduzir os custos operacionais, aumentar a capacidade produtiva e elevar os níveis de serviço e competitividade.

A seguir, pode-se conferir os indicadores de desempenho operacional e financeiro apresentados pela Rumo ALL através do Relatório de Resultados 2017 (COSAN, 2017):

- EBITDA: em 2017 o EBITDA (lucros antes de juros, impostos, depreciação e amortização) da Rumo foi de $\mathrm{R} \$ 2,76$ bilhões, representando um crescimento de $36 \%$ quando comparado a 2016 ;

- Volume transportado: o volume total transportado em 2017 foi de 49,7 bilhões de TKU (toneladas úteis), 28\% maior na comparação com 2016;

- Custo variável ferroviário unitário: houve melhora de 4\% no indicador em 2017, principalmente devido à maior eficiência no consumo de diesel das novas locomotivas; 
- Custo Fixo + Despesas com vendas gerais e administrativas unitário: as meIhoras de $21 \%$ em 2017 refletem principalmente a diluição dos custos fixos devido ao aumento dos volumes transportados;

- Operating Ratio: o indicador, que representa a parcela de custos e despesas como percentual da receita líquida, apresentou melhora significativa quando comparado ao ano de 2016, principalmente em função do aumento no volume transportado, que resultou em diluição de custos, bem como os esforços contínuos da companhia na redução de despesas;

- Consumo de diesel: o indicador apresentou ganhos 9\% em 2017, refletindo maior eficiência no consumo unitário de diesel das novas locomotivas incluídas na operação. Adicionalmente, o aumento no volume de grãos transportados na Operação Norte contribuiu para o resultado, uma vez que o fluxo dessas commodities apresenta um menor consumo médio de combustível (litros/TKB) quando comparado aos fluxos de açúcar oriundos do estado de São Paulo;

- Transit time: $\mathrm{O}$ indicador foi impactado principalmente por interdições em via para execução dos investimentos programados. No entanto, o aumento no tempo de trânsito não impactou o tempo de ciclo de vagões. A operação continuou apresentando ganhos de eficiência que foram refletidos no aumento de volumes transportados em 2017;

- Ciclo de vagões: A melhor operação da Rumo nos terminais em que atua, reduzindo o tempo de carga e descarga das composições, compensou o aumento no transit time nas operações, e resultou na melhora no tempo do ciclo dos ativos;

- Carregamento médio vagões/dia: O indicador refletiu o aumento de capacidade gerada, que permitiu com que a Rumo captasse maiores volumes de grãos. $O$ resultado foi alcançado mesmo com a renovação de frota, em que vagões com menor capacidade foram substituídos por vagões com capacidade para 90 toneladas, o que permite o transporte do mesmo volume com menor número de vagões carregados.

A gestão empresarial, com foco na eficiência e crescimento, estimulou o empreendimento de ações articuladas e específicas, dentro das oportunidades de mercado, que levaram o grupo a não apenas resolver necessidades, mas expandir os negócios. 


\subsection{Receptividade do setor de grãos}

A fusão entre a Rumo e a ALL causou preocupação no setor de grãos, pois foi encarada como uma barreira aos atuantes e entrantes nas áreas de logística e de produção de commodities agrícolas, visto que, na interpretação do setor, a ALL passaria a priorizar cargas da Rumo Logística em detrimento dos demais clientes do setor de soja e milho, gerando restrições de acesso ao mesmo plantel de vantagens competitivas em transportes e armazenagem provenientes dessa nova operação (LEITE; AGNOLIN; CARVALHO, 2017).

A constituição de uma nova empresa no segmento logístico, pelo seu porte e atuação, evidenciou reações por parte dos afetados e interessados. Freitas (2015) destacou também pontos de preocupação com os efeitos da verticalização das operações logísticas, além da nova empresa privilegiar o transporte dos produtos da Raízen (empresa do grupo), a ferrovia deixaria de ser independente, havendo impactos nas tarifas ferroviárias e a renovação automática da concessão ferroviária, condição esta imposta pela Cosan.

Essa nova situação gerou uma preocupação por parte dos produtores de grãos, pois a capacidade de transporte da ALL é limitada em função da falta de investimentos necessários. Muito embora as safras de grãos e açúcar sejam sazonais e ocorram em épocas distintas, a demanda pelo transporte evidencia-se por todo o ano. É um cenário em que atender a um significa sacrificar o outro. $O$ volume de soja e milho é cinco vezes maior que o de açúcar, e o não transporte dos grãos pela ferrovia, direcionaria essa atividade para o modal rodoviário, comprometendo assim a competitividade do produto no mercado internacional (RIOS, 2014).

\section{CONSIDERAÇÕES FINAIS}

Cada empresa busca identificar oportunidades para criar valor ao processo produtivo e logístico como elemento de sua competitividade organizacional. Para tanto, utilizam-se de estratégias de crescimento, destacando atividades fundamentais, que em determinados momentos, são confrontadas com a decisão entre "fazer" ou "comprar". 
A verticalização é uma opção da organização em executar atividades consideradas essenciais para incrementar o processo de crescimento delineado nos planos da gestão dos negócios. Esta alternativa demarcou o comportamento da Cosan, quando investiu na criação da Rumo Logística para o transporte de seus produtos, e mais ainda agora com a recente fusão com a ALL, originando a maior empresa de transporte ferroviário do Brasil.

A fusão da Rumo com a ALL resultou da percepção que a Cosan teve com relação as dificuldades que o agronegócio enfrenta quando o assunto é a logística de transporte dos produtos da safra. A Cosan procurou articular-se no sentido de assegurar que seus produtos cheguem ao Porto de Santos para atender aos compromissos com o mercado internacional de forma competitiva. Dentro do planejamento, consta a aplicação de investimentos na melhoria da infraestrutura, com o intuito de ampliar a malha ferroviária e solucionar os gargalos, tendo como consequência a elevação da eficiência e redução dos custos operacionais.

Esse procedimento da Cosan em constituir uma empresa logística e promover investimentos para melhorias no transporte de produtos do agronegócio gerou expectativas nos produtores, tanto do setor sucroenergético como de grãos, pois a visão concebida foi de que existe a necessidade de investimentos para atender uma demanda de movimentação dos produtos. A eficiência para operação de transporte dos produtos pode significar redução nos custos.

Os contínuos investimentos (reestruturação de processos, renovação de frota, investimentos em via permanente, terminais e pátios) estão proporcionando grandes melhorias operacionais e expansão da capacidade, o que permitiu que a Rumo captasse maiores volumes, diluindo custos, conforme estratégia de geração de valor da companhia. A renovação de frota, em conjunto com outras iniciativas do plano de investimentos, proporcionou um crescimento no custo variável inferior a expansão do volume, com destaque para a redução expressiva no consumo de diesel (Litros/TKB: $-8,6 \%$ ) em 2017 quando comparado a 2016. O aumento da capacidade de transporte gerou ganhos de produtividade e permitiu que a Rumo atingisse recordes operacionais durante o ano de 2017 (COSAN, 2017).

Especificamente no caso do transporte de grãos, operação mais rentável da companhia, o crescimento foi de $39 \%$ na comparação anual. O Porto de Santos (SP), principal destino das cargas transportadas pela Operação Norte, escoou em 2017 um 
total de 36 milhões de toneladas de grãos, forte aumento frente as 27 milhões de toneladas no ano anterior. Mesmo com essa expansão significativa do mercado de exportação, a Rumo alcançou 53\% de market share, 3 p.p. acima de 2016. Esse resultado evidencia o sucesso na execução do plano de investimentos, com expressivo crescimento da capacidade (COSAN, 2017).

Em 2017, o CAPEX (Capital Expenditure) atingiu $R \$ 2.153,5$ milhões, $12 \%$ superior ao ano anterior. Os principais investimentos em aumento de capacidade foram: 1) aquisição de 311 vagões HPT; 2) melhoria da infraestrutura, a fim de eliminar restrições e aumentar a capacidade, e revitalização da via permanente, com substituição de trilhos e dormentes; 3) continuidade do projeto para revitalização da ferrovia na margem direita do Porto de Santos (SP), permitindo uma melhor recepção ferroviária nos terminais; 4) andamento das obras da moega de fertilizantes no terminal de Rondonópolis (MT); e 5) diversas melhorias realizadas em pátios e terminais, com a finalidade de reduzir o tempo de permanência dos trens e aumentar a produtividade da operação (COSAN, 2017).

De maneira geral, alguns líderes atuantes no agronegócio veem essa fusão como uma oportunidade para investimentos em melhorias nas operações de transporte dos produtos, aumento da eficiência na logística ferroviária, diminuição do custo para o produtor, contribuição para solucionar o gargalo logístico do país e redução do custo Brasil. Deixam transparecer que o impacto positivo dessa fusão deve ser percebido não apenas pelo setor sucroenergético, mas por toda a cadeia de exportação do agronegócio. Trata-se de um efeito que já está sendo observado pelas melhorias implementadas pela Rumo, refletindo na desaceleração dos fretes rodoviários, perspectiva de grandes investimentos e maior racionalidade no planejamento do transporte de forma ampla.

\section{REFERÊNCIAS}

AMÉRICA LATINA LOGÍSTICA. Relatório anual 2013. Curitiba: ALL, 2014. Disponível em: http://relatoweb.com.br/all/quem somos.php . Acesso em: 27 jan. 2018.

ARAÚJO, M. J. Fundamentos de agronegócio. 4. ed. São Paulo: Atlas, 2013.

BERTÁGLIA, P. R. Logística e gerenciamento da cadeia de abastecimento. 3. ed. São Paulo: Saraiva, 2016. 
BRASIL, Ministério da Agricultura, Pecuária e Abastecimento (MAPA). Infraestrutura e logística. 2017. Disponível em: http://www.agricultura.gov.br/assuntos/politica-agricola/infraestrutura-e-logistica/infraestrutura-e-logistica . Acesso em: 21 jan. 2018.

CALLADO, A. A. C.; CALLADO, A. L. C. Sistemas Agroindustriais. In. CALLADO, A. A. C.; CALLADO, A. L. C (Org.). Agronegócio. 4. ed. São Paulo: Atlas. 2015. p. 1-21.

COSAN S. A. Quem somos: excelência em energia e logística, São Paulo, 25 jan. $2018 a$. Disponível em: http://cosan.com.br/pt-br/cosan/quem-somos . Acesso em: 25 jan. 2018.

COSAN S. A. Raízen: destaque em energia, São Paulo, 26 jan. 2018b. Disponível em: http://cosan.com.br/pt-br/negocios/energia/raizen. Acesso em: 26 jan. 2018.

FREITAS, T. Empresas exportadoras de grãos tentam restringir fusão na logística. Folha de S. Paulo, São Paulo, 10 fev. 2015. Mercado. Disponível em: http://www1.folha.uol.com.br/mercado/2015/02/1587687-empresas-exportadoras-de-graostentam-restringir-fusao-na-logistica.shtml . Acesso em: 21 jan. 2018.

FREITAS, J. de; ANDRADE, L.; BORDEAUX-REGO, R. Crescimento orgânico: uma análise da estratégia de expansão das lojas americanas. In: CONGRESSO NACIONAL DE EXCELÊNCIA EM GESTÃO. Anais... Rio de Janeiro: CNEG \& INOVARSE, 2015.

GARCIA, J. R.; LIMA, D. A. L. L.; VIEIRA, A. C. P. A nova configuração da estrutura produtiva do setor sucroenergético brasileiro: panorama e perspectivas. Revista de Econonia Contemporânea, Rio de Janeiro, v. 19, n. 1, p. 162-184, jan./abr. 2015. DOI: http://dx.doi.org/10.1590/198055271917

LEITE, A. A. V.; AGNOLIN, C. T.; CARVALHO, C. E. Fusão entre ALL - América Latina Logística e Rumo Logística Operadora Multimodal: uma análise a partir da visão baseada em recursos. Revista Inteligência Competitiva, São Paulo, v. 7, n. 1, p. 91-128, jan./mar. 2017. DOI: http://dx.doi.org/10.24883\%2Fric.v7i1.208

MOBUS, S. Verticalização e terceirização das atividades logísticas: estudo de casos múltiplos no setor químico. 2012. 120f. Dissertação (Mestrado em Administração) - Universidade Federal do Rio Grande do Sul, Porto Alegre, 2012.

MOBUS, S.; MAÇADA, A. C. G. Verticalização e terceirização das atividades logísticas: estudo de casos múltiplos no setor químico. In: ENCONTRO DA ANPAD,37., 2013. Anais... Rio de Janeiro, 7 a 11 de setembro de 2013.

PRODANOV, C. C.; FREITAS, E. C. Metodologia do trabalho científico: métodos e técnicas da pesquisa e do trabalho acadêmico. 2. ed. Novo Hamburgo, RS: FEEVALE, 2013.

RIOS, C. Setor de grãos quer barrar a fusão da ALL com a Rumo. Gazeta do Povo, São Paulo, 20 mar. 2014. Transporte. Disponível em: http://www.gazetadopovo.com.br/economia/setor-de-graos-quer-barrar-fusao-da-all-com-a-rumo-1zk8wr9iga8tk1shmvw45bxhq . Acesso em: 21 jan. 2018.

RITZMAN, L. P.; KRAJEWSKI, L. J. Administração da produção e operações. 8. ed. São Paulo: Pearson Prentice Hall, 2009.

RUMO. Formulário de referência - 2016. Rumo Logística Operadora Multimodal S. A. Curitiba: $R U M O, 2016 a$. 
RUMO. Ferrovia e o agronegócio: reunião da câmara temática de infraestrutura e logística - CTLOG. Curitiba: RUMO, 2016b. Disponível em: http://www.agricultura.gov.br/assuntos/camaras-setoriais-tematicas/documentos/camaras-tematicas/infraestrutura-e-logistica/anos-anteriores/a-ferrovia-e-o-agronegocio-rumo-51.pdf. Acesso em: 21 jan. 2018.

RUMO. Relatório de Resultados 4T17. Curitiba, 2017. Disponível em: http://ri.rumolog.com/ptb/9201/02.03.2018ReleaseVF PORTVF.pdf . Acesso em: 23 jan. 2018.

RUMO. A empresa. Curitiba, 26 jan. 2018. Disponível em: http://pt.rumolog.com/conteudo pti.asp?idioma=0\&tipo=27307\&conta=45 . Acesso em: 26 jan. 2018.

RYDLEWSKI, C. Os segredos da fusão Rumo-ALL. Revista Época Negócios, Porto Alegre, RS, 2014. Disponível em: https://epocanegocios.globo.com/Informacao/Resultados/noticia/2014/08/os-segredos-da-fusao-rumo-all.html . Acesso em: 26 jan. 2018.

UNIÃO DA INDÚSTRIA DE CANA-DE-AÇÚCAR - UNICA; CENTRO NACIONAL DAS INDÚSTRIAS DO SETOR SUCROENERGËTICO E BIOCOMBUSTÍVEIS - CEISE Br. Setor sucroenergético no Brasil: uma visão para 2030. São Paulo, 2016. Disponível em: http://www.mme.gov.br/documents/10584/7948692/UNICA-CEISE Setor+Sucroenerg\%C3\%A9tico+no+Brasil Uma+Vis\%C3\%A3o+para+2030.pdf/80da9580-60c7-4f53-afaf030ad01f3ebf;jsessionid=AC802B166C93389BED1AB445EAB7CD10.srv155 . Acesso em: 26 jan. 2018

UNIÃO DA INDÚSTRIA DE CANA-DE-AÇÚCAR - UNICA. Relatório final da safra 2016/2017 - Região Centro-Sul. São Paulo, 2017a. Disponível em: http://www.unicadata.com.br/listagem.php?idMn=95 . Acesso em: 21 jan. 2018.

UNIÃO DA INDÚSTRIA DE CANA-DE-AÇÚCAR - UNICA. Etanol já evitou a emissão de 408,4 milhões de toneladas de co2 desde 2003. 2017b. Disponível em:

http://www.unica.com.br/noticia/39864125920332180623/etanol-ja-evitou-a-emissao-de-408por-cento2C4-milhoes-de-toneladas-de-co2-desde-2003/ . Acesso em: 26 jan. 2018.

VIAN, C. E. F.; MARIN, F. R. Árvore do conhecimento cana-de-açúcar. Campinas, SP: EMBRAPA, 2017.

VINHAS, H. A Verticalização como ferramenta de crescimento e redução de custo. Revista. Lagos, Volta Redonda, RJ, v. 8, n. 2, p. 39-49, jul./dez. 2017. Disponível em: http://www.revistalagos.uff.br/index.php/lagos/article/view/272 . Acesso em: 24 jan. 2018.

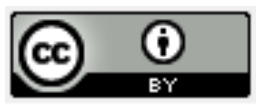

Artigo recebido em: 02/07/2018 e aceito para publicação em: 13/04/2019 DOI: http://dx.doi.org/10.14488/1676-1901.v19i2.3306 